\title{
Zinc complexes with nitroderivatives of quinolin-8-ol
}

\author{
M. Harmošová ${ }^{1}$, E. Samol'ová² ${ }^{2}$ N. Kuncová ${ }^{1}$, I. Potočňák ${ }^{1}$ \\ ${ }^{\text {I} D e p a r t m e n t ~ o f ~ I n o r g a n i c ~ C h e m i s t r y, ~ I n s t i t u t e ~ o f ~ C h e m i s t r y, ~ P . ~ J . ~ S ̌ a f a ́ r i k ~ U n i v e r s i t y ~ i n ~ K o s ̌ i c e, ~ M o y z e s o v a ~ 11, ~} 04001$ Košice, \\ Slovakia \\ ${ }_{2}^{2}$ Institute of Physics of the Czech Academy of Sciences, Na Slovance 2, 18221 Prague, Czech Republic \\ michaela.krescankova@student.upjs.sk
}

Five new zinc(II) complexes, $\left\{\mathrm{Na}\left[\mathrm{Zn}(\mathrm{ClNQ})\left(\mathrm{SO}_{4}\right)\left(\mathrm{H}_{2} \mathrm{O}\right)\right]\right\}_{n} \quad(\mathbf{1}), \quad\left[\mathrm{Zn}(\mathrm{dNQ})_{2}\left(\mathrm{H}_{2} \mathrm{O}\right)_{2}\right] \cdot 1$,4-dioxane (2), $\left[\mathrm{Zn}(\mathrm{dNQ})_{2}\left(\mathrm{H}_{2} \mathrm{O}\right)_{2}\right] \quad(\mathbf{3})$, $\mathrm{NH}_{2}\left(\mathrm{CH}_{3}\right)_{2}\left[\mathrm{Zn}(\mathrm{ClNQ})_{3}\right] \cdot \mathrm{DMF}$ (4) and $\mathrm{K}\left[\mathrm{Zn}(\mathrm{ClNQ})_{3}\right] \cdot 2 \mathrm{DMF}$ (5), (HClNQ = 5-chloro-7-nitroquinolin-8-ol, HdNQ = 5,7dinitroquinolin-8-ol (Fig.1)) have been prepared. All complexes were characterized by IR spectroscopy, elemental analysis and X-ray structure analysis.
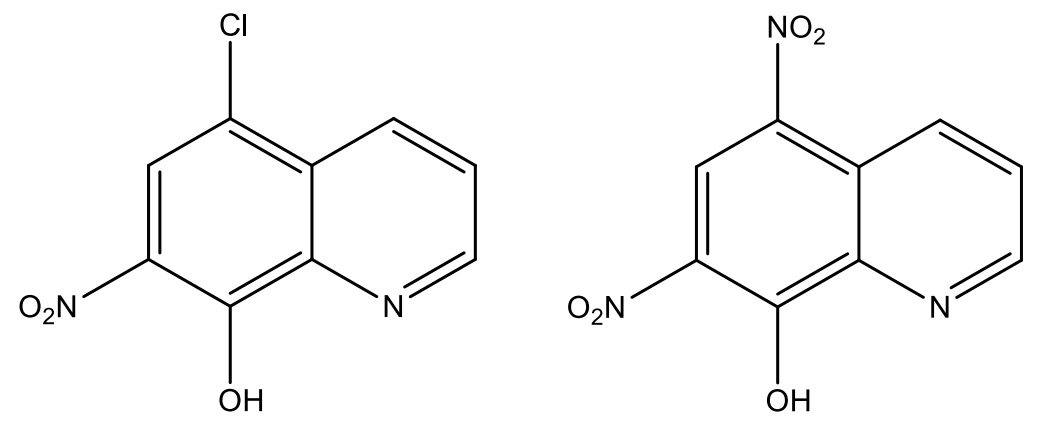

Figure 1. Chemical structures of HCINQ (left) and HdNQ (right)

Complex 1 has a polymeric structure. Zn(II) atom is penta-coordinated by one bidentate molecule of CINQ ligand, one molecule of water and a pair of crystallographically equivalent sulfate anions, which interconnect adjacent zinc atoms to form a zig-zag chain. In addition, the central atoms are also connected through ionic interactions between oxygen atoms with a partial negative charge and sodium cation.

Complexes 2 and 3 have similar molecular structures, $\mathrm{Zn}(\mathrm{II})$ atom sits at the center of the symmetry, therefore only a half of the molecule is independent. In their crystal structures, there are two trans-coordinated dNQ molecules in the equatorial plane while two water molecules occupy axial positions, forming a deformed octahedral geometry. Complex 2 also contains one uncoordinated molecule of 1,4-dioxane.

Complexes $\mathbf{4}$ and $\mathbf{5}$ are ionic compounds with very similar structures, in which $\mathrm{Zn}$ (II) atom is tris-coordinated by molecules of deprotonated 5-chloro-7-nitro-quinolin-8-ol with nitrogen and oxygen donor atoms coordinated in mer-fashion. The negative charge of the complex anions is counterbalanced by uncoordinated dimethylammonium and potassium cations, respectively, and interesting orientation of the oxygen atoms to $\mathrm{NH}_{2}\left(\mathrm{CH}_{3}\right)_{2}{ }^{+}(\mathbf{4})$ and $\mathrm{K}^{+}(\mathbf{5})$ ions is observed. In addition, the complex 5 contains one more solvated molecule of DMF molecule.

Keywords: 5-chloro-7-nitroquinolin-8-ol; 5,7-dinitroquinolin-8-ol; zinc

Slovak Grant Agencies (VEGA 1/0148/19, VVGS-PF-2020-1425 and VVGS-PF-2021-1772) are acknowledged for financial support. 